\title{
The role of mate-guarding behavior in old Kuwait dwellings
}

\author{
A.-M. Al-Ballam \\ Department of Architecture, College of Architecture, \\ Kuwait University, Kuwait
}

\begin{abstract}
The design of dwellings are indirectly affected by the consequences of mateguarding behavior performed by many male Homo sapiens. Evidence of such influence is perceived in the design of many vernacular dwellings dominated by conservative inhabitants. To prove this hypothesis, the current investigation identified the strategies of mate-guarding behavior in some animals then compared these findings with the design meanings of some dwellings found in old Kuwait City. The purpose of this comparison is to test the degree of similarities between the objectives of mate-guarding behavior in nature and the objectives of design strategies for some spontaneous architecture. Proving this hypothesis can lead to an evolutionary interpretation for the design of some vernacular dwellings.
\end{abstract}

Keywords: architecture, vernacular, mate-guarding, survival, old Kuwait City.

\section{Introduction}

\subsection{Mate-guarding behaviour is an evolutionary necessity}

The natural behaviour to guard the mate is an effective survival tool evolved in H. sapiens males. It is a built-in reaction of fear and rage intended to sustain access to sexual mates, avoid the violation of sexual rivals, and prevent a female partner from deserting the mate-ship [1]. It maintains and extends the male's private association of intimacy, and protects it from the treachery of disloyalty [2]. Additionally, mate-guarding behaviour influences the relationship of the individual male with other members of his community, and determines his rank in society [3]. Any H. sapiens male not having an inclination toward guarding 
their mates may have consumed all his time rearing the descendants of other males and the genes coding for such tendencies were long ago eliminated [3]. The presence of an innate evolutionary behavior like mate-guarding in humans is closely related to the existence of anxiety, nervousness and insecurity in his private relationship of intimacy.

\subsection{Questions igniting the research}

Mate-guarding behavior seems to affect a great portion of $H$. sapiens male's physical action. Based on this fact, a number of significant inquiries related to the built environment have been ignited: Is there a relationship between male mate-guarding behavior and the form of some spontaneous inhabited structures? Did this association affect the outcome of architecture throughout history? Can the after math of mate-guarding behavior be recognized physically through architecture? If yes, then how can this observation affect and change our understanding of built environments? In what sense can such a discovery modify the future education and research of architectural history and theory? These are some questions that have ignited the current research.

\subsection{Lack of scholarly efforts}

Male mate-guarding behavior has barely been considered as a reason or factor for the production of shelters in scientific architecture research. On the contrary, male mate-guarding behavior is often viewed as an intangible mental phenomenon that does not manifest into touchable physical aftermaths. Frequently, researchers substitute this term with relatively general definitions such as "self-protection" or "group-defense"; however, evolutionary reasons behind the acts of shielding a mate or guarding a companion are often marginalized and overlooked.

A review of the literature about architecture and human behavior proves this rarity. In his 1969 book House Form and Culture, Amos Rapoport acknowledges the role of protecting female partners and close relatives in the construction of vernacular dwellings; nevertheless, he did not provide an explanation for the origin of this phenomenon [4]. Although his argument is built partly upon some Darwinian standpoints, he does not mention precise evolutionary reasons behind the act of guarding and shielding female mates, reflected through architectural products. In their book titled Culture and Environment, published in 1980, Irwin Altman and Martin Chemers voyaged little beyond the straightforward human behavioural explanation of Rapoport. They adapted a direct evolutionary point of view by giving substantial weight to territorial human behavior in the origination of living habitats [5]. However, there were no direct referrals to the male behavior of mate-guarding in their book. In his book Dwellings, Paul Oliver indicated that this phenomenon of separating male and female areas in some vernacular structures exists mainly because of the different social and economic roles of males and females [6]. Similarly, mate-guarding factors were also disregarded. Overall, most publications on architecture based on human behavior avoid using the term "mate-guarding" to explain spatial segregation on the basis 
of gender in a spontaneous manmade environment. Rarity in research tackling the influence of mate-guarding behavior in architecture habitats invigorated the mission of this study.

\subsection{The hypothesis}

Intrigued by the above mentioned value of male mate-guarding behavior, questions, and state of rarity in scholarly research, the following research attempts to prove the hypothesis that male mate-guarding behavior has affected the design decisions of some vernacular architecture forms throughout history. It attempts to prove that some architecture elements act as a tool to guard mates.

\section{The Methodology}

\subsection{The method of testing}

The research is built upon a qualitative method of research. Testing the hypothesis of the research was built upon assessment model aims to compare strategies of mate-guarding found in nature, specifically animals, with vernacular architectural tactics of protecting female partners, adapted in some $H$. sapiens communities. The aim of this evaluation is to check the extents of similarities and transitivity between these two, often considered, distant behaviors. Comparing the performance generated by animals, and behaviors influenced by non-animated forms, like architectural structures, required the concentration on an intermediary ground for investigation. To make this link valid, the process of comparison focuses on the end result (the function) of some architectural elements. Fundamentally, the investigation looks into the reason behind the construction of such elements and attempts to see if these motives are parallel to reasons of mate-guarding behaviors found in animals.

\subsection{The limits of the research}

Generally, the research argues for a broad hypothesis, however, the necessity to reach an objective result in an appropriate period of time required limiting the research's scope to specific geographical locations, historical phase of time, and exact human gender. The investigation was centred on revealing the embodiment of mate-guarding behavior in the built environment of "Kuwait City" before the independent of the city from the British Empire in 1962. Kuwait City was chosen because of its close proximity to where the research was conducted. Thus, data about the environment were accessible for site visits and testing. To draw the time limits, the investigation was narrowed to the pre-independence era of Kuwait City, specifically the decade of the 1950s. In this period, one could witness Kuwait City's last untainted vernacular architecture arrangement. After this decade, Kuwait City began to rapidly lose its genuine spontaneous Arab Islamic fabric, as the spread of wealth emerging out of the recently discovered oil forced a rapid change in the city's configuration [7]. Last, the research focused on the mate-guarding behavior performed by male Kuwaitis only as it is 
much obvious to physically see the aftermath of male mate-guarding behavior compared with that of the female.

\section{The analysis}

The following section is divided to two main parts: 1) data analysis about the behaviors of mate-guarding in nature; and 2) data analysis about mate-guarding techniques in the built environment of Kuwait city during the 1950s. Detailed illustrations and descriptions of these results follow.

\subsection{Behaviours of mate-guarding in nature}

In general, the data analysis revealed five major strategies of mate-guarding in nature. Detailed illustrations and descriptions of these strategies follow.

\subsubsection{Strategy 1: hiding the mate from intersexual opponents}

Hiding a sexual mate or concealing its attractive signals from a rival male is one of the most straightforward and widespread techniques to guard a female partner. For example, the practice of casing an attractive signal of a mate is seen in the behavior of some bees and moth species, as they usually discharge scents to conceal their mates' smell or make their sexual companions less striking to competitors [8]. In some locust species, the males construct a territorial "barrier" around the female to physically prevent other males from winning sexual contact, if necessary [9]. Hypothetically, this act is not much different from the physical wall erected around $H$. sapiens' dwellings. Similar to many invertebrates, many human males force the female to wear a veil. This act has been practiced in many traditionally conservative societies throughout the history of mankind.

\subsubsection{Strategy 2: removing the mate from the locality of rivals}

Another strategy of mate-guarding, revealed by the data analysis, is the removal of the mate from the proximity of rivals. In certain flying insects, males that succeed in courting a female apply this strategy by flying away with their partners dangled beneath them, removing their females from the proximity of any other nearby males [10]. The male of Japanese beetle display such behaviour by remaining in a tandem formation on their mate for quite a long time $[11,12]$. Similarly, water-strider males ride on the backs of their mates for a relatively long duration to prevent the encroachment of other males, even when not engaged in copulation [13]. Certain male grasshoppers maintain close contact with the female prior to copulation, with the purpose of preventing other males from gaining proximity to their females [9]. All these behaviours are examples of mate-guarding tactics that aim to remove female mates from the locality of male rivals.

\subsubsection{Strategy 3: physically preventing rival males from attaining mates}

Another common method of mate-guarding in primates is the strategy of physically fighting a rival male. Most of the time, this strategy is applied to 
prevent rival males from taking over a receptive female [14]. Adult male baboons often engage in mate-guarding of fertile females by being vigilant in fighting off any males that might disrupt the consortship during mating seasons [15]. Successful fighting skills allow male baboons to preserve exclusive access and obtain fertilized females. Lions, elephants, and chimpanzees are also known for performing an obvious act of this tactic. No exception, jealous male $H$. sapiens also adapts this strategy to prevent rival males from gaining receptive female mates [16]. Physically fighting a sexual opponent is one of the most common techniques of mate-guarding that is practiced by many creatures.

\subsubsection{Strategy 4: monitoring and intimidating the female mate}

The behaviour of monitoring and guarding a female is another straightforward strategy of mate-guarding that is found in nature. When living in a multi-male group, silverback gorillas increase their attempts to remain near receptive females by persistently following them and "neighing" sometimes [17]. Some male gorillas use coercion to persuade the female to mate [18]. Although most apes build nests on trees, a recent study shows that some apes often perform ground-nesting behavior underneath trees where a certain female sleeps [19]. Typically, the ape accomplishes this task by bending, breaking, and interweaving branches into a circular setting, followed by inserting smaller branches to form a robust but contented sleeping area [19]. Male apes do that to mate-guard a female on the tree from predators and nearby sexual rivals [20]. This behavior is one of the few nonhuman signs of using nests or shelters as an agent to mateguard. Monitoring and intimidating a receptive female is one of the most precautionary techniques of mate-guarding behavior.

\subsubsection{Strategy 5: muting the exposure of courting and copulation}

Another strategy arising from mate-guarding instinct is the behavior of muting the exposure of sexual activities to avert rival attention away from a potential reproductive mate. For example, the initially noisy reproduction calls of some cricket and katydid species become hushed to "softer courtship chatter" as a male succeeds in attracting a female [19]. According to Buss, the clear human desire to hide sexual interaction echoes similar tactics of some invertebrates to reduce the conspicuousness of copulation and hence evade potential interference or disruption by others [9]. Muting the noticeable copulation are natural strategies adapted by some animals and humans alike to decrease the probability of rivals recognizing and seizing a receptive female mate.

\subsection{Mate-guarding strategies in Old Kuwait City}

With mate-guarding strategies in the animal kingdom having been revealed, the subsequent part analyzes data about the built environment of Kuwait City during the 1950s. This part discloses the existence of six major architectural design strategies that aim significantly toward the mate-guarding of female mates. Detailed illustrations and descriptions of these six strategies follow. 


\subsubsection{Design strategy 1: reducing the presence of windows on ext-walls}

One of the most obvious design strategies found in private Kuwaiti dwelling of the 1950 s and that aims to mate-guard females is the policy of reducing the presence of darayish (windows) on the house's peripheral walls. Regularly, the derisha (single of darayish) is constructed to overlook private inner uncovered courtyards [20]. If it was essential to create one on an exterior wall, the size of derisha made small and placed in a lofty position, usually at a level higher than normal adult human height (Fig. 1(a)) [21]. Such construction strategies act as physical solutions to prevent exposing the physical appearance of female partners to adult male impostors. This architectural solution produces analogous effects to the tactics of covering attractive signals of female partners discussed in the previous section.

\subsubsection{Design strategy 2: enforcing vulnerable elements}

In the typical Kuwaiti dwelling during the 1950s, vulnerable elements, such as the bab al-sikah (main exterior door) or the derisha, were made of robust materials and supported with steady tools to make them withstand unauthorized penetration. For example, the derisha is often protected with tight wooden or steel grill-like elements from the outside, and it is often covered with wooden shutters that occasionally open from the inside (Fig. 1(b)). The external grill combined with the inner shutter elements is a complete architectural strategy aimed primarily for various protective reasons, especially if the derisha is overlooking a public street [22, p. 66]. One main function of the classic 1950s Kuwaiti derisha construction was to protect and seclude females; it hid them, but barely restricted their vision [23]. The design and location of a typical 1950s Kuwaiti derisha is an exclusive unique architectural solution that was influenced highly by the behavior of serving and protecting female inhabitants, which was often a result of male's mate-guarding behavior.

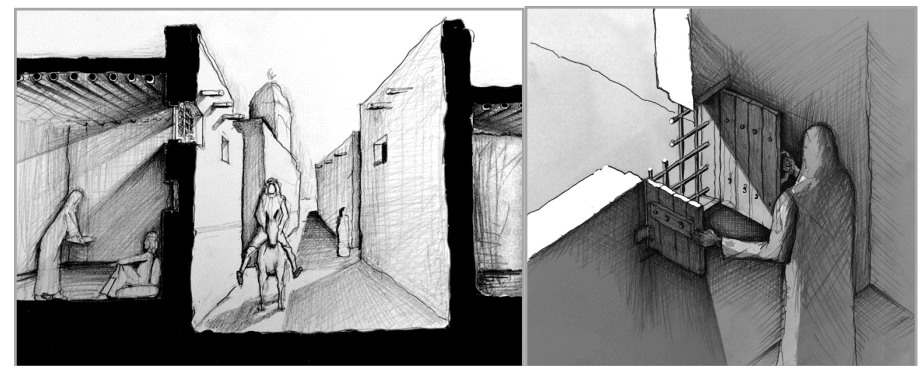

(a)

(b)

Figure 1: (a) Section through a typical Kuwaiti house showing the placement of window openings in a high position.(b) 3D section through a typical derisha in a 1950s Kuwaiti house (source: the author).

Usually, the bab al-sikah, the main exterior door of a typical Kuwaiti dwelling of the 1950s, was constructed out of two large sides that were rarely opened; however, one of the two wooden sides often had an imbedded smaller 
sized wooden door (Fig. 2(a)) [24]. Frequently, the transition process, from the outside to the inside, or vice versa, happened through the small inset door; the two large sides of the door were opened only when an outsized animal or large object had to be passed through [22, p. 58]. To prevent easy entry of intruders, the bab al-sikah was supported with a tool called chellab, a long bended steel bar to push the door from inside (Fig. 2(b)). The design of both the bab al-sikah and derisha in a typical Kuwaiti dwelling of the 1950s illustrate two obvious strategies of protecting female member by preventing an easy break to inner territory.

\subsubsection{Design strategy 3: inserting a buffer space}

In a typical 1950s Kuwaiti house, the bab al-sikah opened into a transitional space called the dehreeze, which was often erected to minimize the direct observation of the house's interiors (Fig. 2(c)) [22, p. 58]. The 1950s Kuwaiti dwelling often integrates a piece of fabric to isolate the private courtyard space from the semi-public dehreeze space [22, p. 70]. The typical design solution of constructing multiple buffers before reaching the private open courtyard constituted a general defensive strategy that is realized in many dwellings located in the Arab Islamic region [25]. Such solution proves that the multiple barrier strategy, found in the dwellings of Kuwait City during the 1950s, was partly a consequence of the male's tendency to guard his female mates.

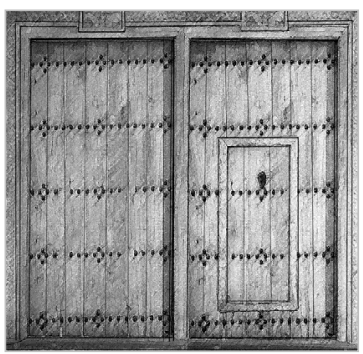

(a)

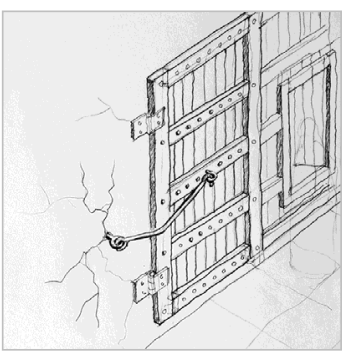

(b)

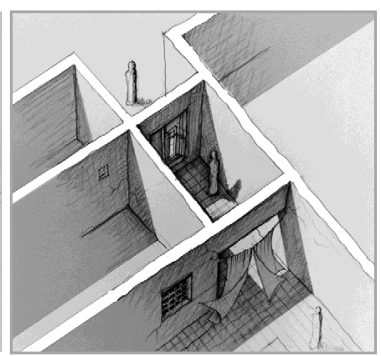

(c)

Figure 2: (a) Sketch of a typical Kuwaiti door; (b) Sketch of a typical chellab insuring the shutting of a main door; (c) Sketch of typical dehreeze in typical vernacular Kuwaiti house (source: the author).

\subsubsection{Design strategy 4: segregating female and male spaces}

Another physical embodiment of mate-guarding behavior often observed in the dwelling of the 1950s Kuwait City was the strategy of segregating female physical spaces from the male ones. For instance, the hoash al-hareem (women's courtyard) was a common section dedicated for female members that usually was found in typical Kuwaiti dwellings during the 1950s. On the other hand, the diwaniya or majlis was a distinctive relatively large room, sometimes built to receive male guests only (Fig. 3(a)). Occasionally, the hoash al-hareem was located in a secluded area away from the main door, whereas the diwaniya was usually located near the main entrance (Fig. 3(b)) [26]. Generally, the segregation 
strategy between males and females assisted in reducing male interactions with female members of the house.

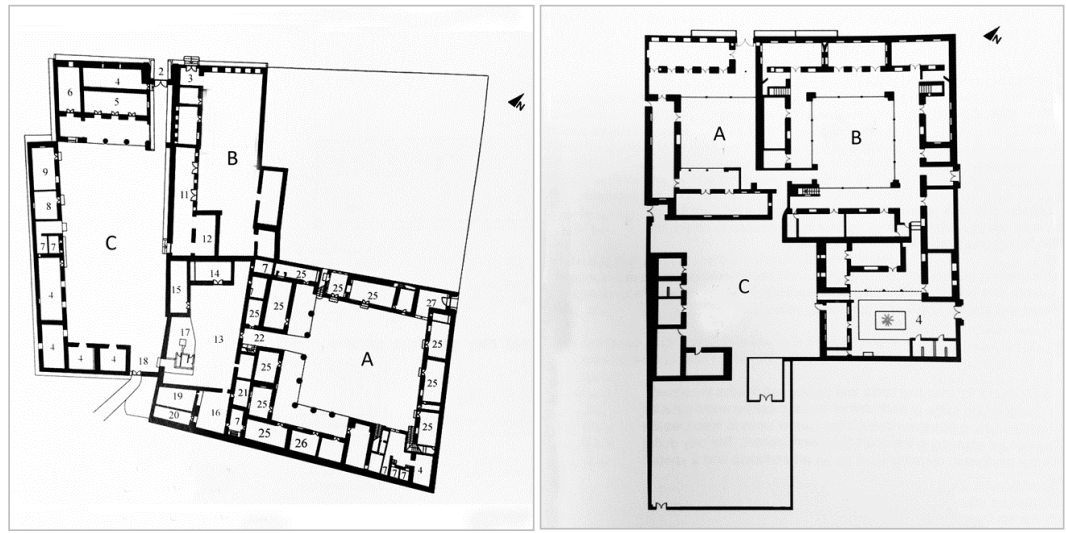

(a)

(b)

Figure 3: (a) Plan of Bait Al-Badir shows diwaniya (A), hoosh harem (B), and men's section (C); (b) Plan of Bait Al-Ghanim shows men's courtyard (A), women's courtyard (B) and animal's section (C) (source: the author).

The hoash al-hareem and diwaniya are apparent in houses of high-income citizens, such as a sheikh, a noble, or a socially significant member of society who often entertained genetically distant male visitors. For low-income houses with limited spaces inside, male visitors were habitually received on an exterior bench placed close to the main door, called datcha (Fig. 4(a)) [22, p. 67]. It is a significant element of many Kuwaiti houses, constructed with the aim of segregating the genetically related females from genetically unrelated males. Datcha, hoash al-hareem, and diwaniya are indirect reflections of male's mateguarding behavior, widely spread in the society of 1950s Kuwait City.

\subsubsection{Design strategy 5: minimizing the female's presence in public urban spaces}

In the Kuwait City of the 1950s, some architectural design strategies are aimed to minimize the female's presence in public spaces. The musaqafa (flying pedestrian bridge physically connecting two isolated houses) is an obvious example of physically applying this strategy. Typically, the function of musaqafa in the 1950s Kuwaiti urban environment was to connect two genetically related houses separated by a minor or major street (Fig. 4(b)) [21]. This architectural tactic allowed female members to move between two properties without getting exposed to genetically unrelated males. Triggered by the inner desire to guard female members and the fear of fragmentation in the clan, musaqafa further enriches the three-dimensional experience of the vernacular city of Kuwait. It can be strongly linked to male behavior of mate-guarding and the fear of physical isolation among genetically close related human individuals. 


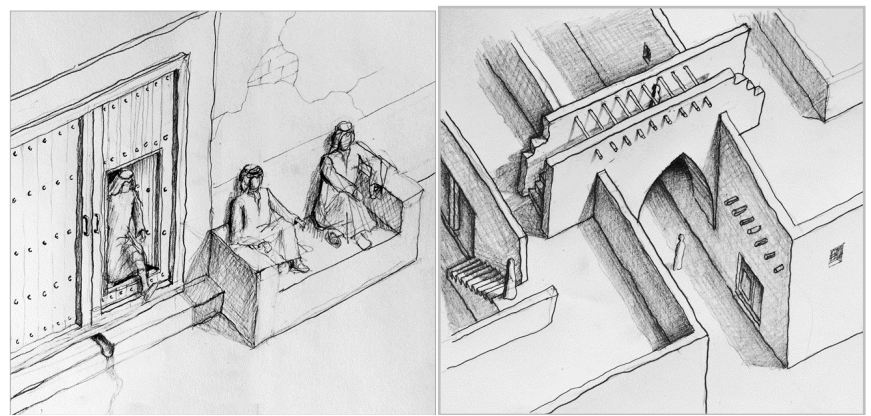

(a)

(b)

Figure 4: (a) Hypothetical sketch of a typical datcha next to the main door of a typical Kuwaiti house during the 1950s; (b) Hypothetical sketch of typical musaqafah connecting two houses in Kuwait City during the 1950s (source: the author).

\section{Verifying the hypothesis}

The matrix shown in Table 1 below illustrates in a cross check manner the similarities in function between some architectural design strategies with mateguarding strategies. Table 2 illustrates in cross check manner similarities in function of mate-guarding strategies found in nature and some architectural mate-guarding elements in Kuwait City during the 1950s. In general, Tables 1 and 2 reveal the following facts:

a. The strategy of segregating the male and female spaces in a specific dwelling in Kuwait City during the 1950s is considered the most successful architectural element in guarding the female mate, because it contains all functions of mate-guarding found in nature.

b. The strategy of hiding female mates from male opponents was the most motivating function for the erection of mate-guarding architectural design strategies in Kuwait City during the 1950s.

c. The strategy of monitoring and intimidating female mates and muting sexual activities are the least two functions that influence the erection of elements discussed above.

d. Hoash al-hareem is the most effective architectural elements in mateguarding females that can be found in Kuwait City during the 1950s.

e. The datcha is the least effective architectural design strategy in guarding female mate that can be found in Kuwait City during the 1950s.

Primarily, the strategies revealed in the previous section are innately adapted by animals and humans to prevent rivals from attaining receptive female partners. Mate-guarding behaviour evolved in animals and H. sapiens to curtail, slow, or prevent mate poaching or mate defection, even while maintaining one's own access to the reproductively relevant resources of one's mate. For a male living in Kuwait City during the 1950s, adapting mate-guarding behavior 
through dwelling design was another successful evolutionary tool that aimed to preserve his mate and empower his genetic line.

Table 1: Matrix illustrates similarities in function between some architectural design strategies with mate-guarding strategies (source: the author).

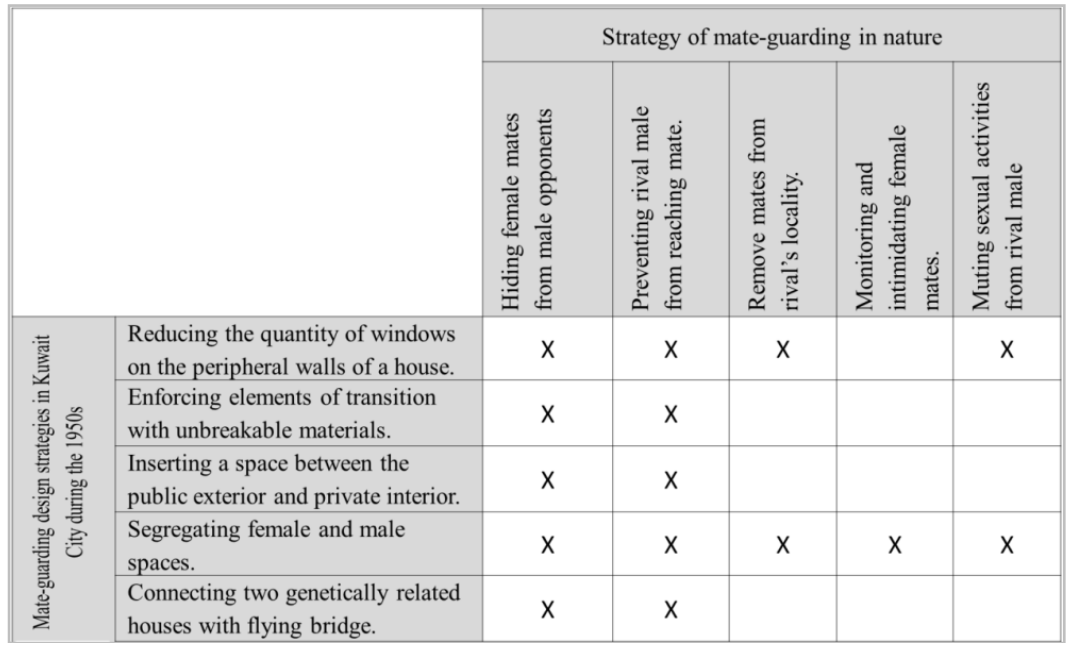

Table 2: Matrix illustrating the functions of some architectural mate-guarding elements found in Kuwait City during the 1950s from the perspective of mate guarding strategies found in nature (source the author).

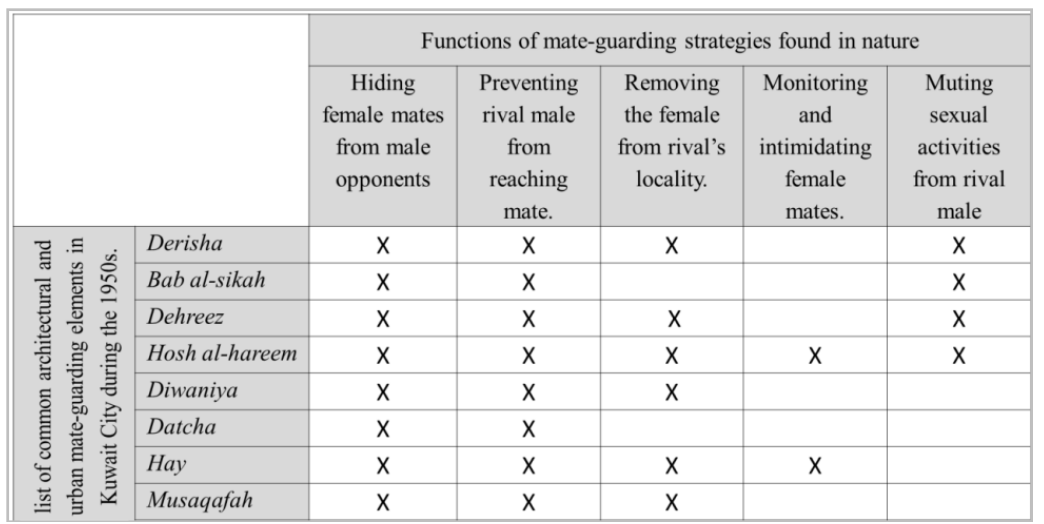

\section{The results}

The above verification process proved that male Kuwaitis during the 1950s adapted and articulated some architectural products to act as mate-guarding instruments to protect their sexual partners. Such forms not only aided in 
protecting the general inhabitants from unexpected external danger but also increased the certainty of a male's paternity delivered by female sexual partners. Examples of the physical embodiment of male mate-guarding behavior are clearly visible in vernacular architecture, as they often present an imprint of direct reaction of human natural needs. In particular, the Kuwait City of the 1950s presented constructive examples that crown the relationship between male mate-guarding behavior and manmade structure.

Often perceived as general protective elements, many architectural strategies contained, additionally, functions that aimed to hide, cover, and protect female members of specific households. Exterior walls were often designed with fewer windows; additionally, they were often accompanied with tight steel or plaster grills from the outside and wooden shutters that opened from the inside. Main doors in Kuwait City of the 1950s also reflected some mate-guarding strategies. They did not open directly to courtyards habitually occupied by females, and they were often imbedded with a built-in smaller door, making the process of violating the interior more difficult for intruders. To further isolate female members from sexual rivals, pre-independent Kuwaiti houses were often designed with designated sections for female and male members. Additionally, the vertical expansion of some dwellings and the existence of pedestrian bridges between houses were two strategies aimed partly to eliminate a female's exposure during her transition between her dwelling and genetically related neighboring houses. All the above-mentioned architectural design strategies aimed to reduce the chance of exposing mates and genetically related female to male visitors or trespassers.

The ultimate purpose of the above-mentioned architectural solutions was to prevent mate poachers from accessing female partners while simultaneously preventing her from deserting the mate-ship or socially insulting her male. Such methods of construction aided the typical 1950s Kuwaiti male in reducing his paternal uncertainty and strengthening his genetic pool. Such functions are analogous to strategies acted out among primitive living organisms when they are subjected to emotions evoked by male mate-guarding behavior. This hypothesis can verify the evolutionary roots of many architectural products, especially those that get constructed in a spontaneous manner.

\section{Conclusion}

In conclusion, this research illustrated the critical role of male mate-guarding behavior in the formation of pre-independent Kuwait City, in particular. The combination of the innate drive to guarding the mate, fear of social seclusion, anxiety of social humiliation, and panic of afterlife condemnation have pressed many conservative male house holders in the city during the 1950s to adapt some unique built-up solutions. These strategies are successful physical tools to strengthen the male's genetic pool and elevate his statues in the community. Failure to adapt mate-guarding behavior through architecture can lead to a total waste of individual's energy and time, and may cost him the battle of dominating the environment. 
This investigation presented a point of view that can greatly adjust the current approach of analyzing, comprehending, and interpreting vernacular architecture. This sighting can push architectural historians, theoreticians, and behaviorists to reinterpret their studied materials through recent findings in evolutionary biology, anthropology, and sociobiology. The implications of male mateguarding behavior in architecture and urban environment is not only confined to Kuwait society during the 1950s; it can be observed spread widely in many vernacular societies throughout the history of mankind. Throughout history, many vernacular architectural elements are indirect strategies of mateguarding - a "secondary veil" for female group members that is a result of innate instincts and strict devout and social traditions. Most vernacular architecture are indirect reflection of natural elements; they are no different from any product of nature, and they are greatly subject to various evolutionary forces, such as male mate-guarding behavior.

\section{References}

[1] David Buss, "From Vigilance to Violence: Tactics of Mate Retention in American Undergraduates", Ethology and Sociobiology, 9. 5 (1988), 291317.

[2] David Buss, The Dangerous Passion: Why Jealousy is as necessary as Love and Sex, New York, NY, USA: Free Press, 2000; David Buss, "Human Mate Guarding", Neuroendocrinology Letters, 23.4 (2002) ,2329.

[3] Jack Palmer and Linda Palmer, Evolutionary Psychology:The Ultimate Origins of Human Behavior, Naam, USA: Pearson, 2002.

[4] Amos Rapoport, House Form and Culture, Englewood Cliffs, NJ, USA: Prentice-Hall, 1969.

[5] Irwin Altman and Martin Chemers, Culture and Environment, London, UK: Cambridge University Press, 1980.

[6] Paul Oliver, Dwellings: The Vernacular House World Wide, London, UK: Phaidon Press Ltd, 2003.

[7] Yasser Mahgoub, "Architecture and the Expression of Cultural Identity in Kuwait”, The Journal of Architecture, 12. 2 (2007), 165-182.

[8] Randy Thornhill and John Alcock, The Evolution of Insect Mating Systems, Cambridge, MA, USA: Harvard University Press, 1983.

[9] David Buss, "Human Mate Guarding", Neuroendocrinology Letters, 23. 4 (2002), 23-29.

[10] Mark Cooper and Steven Telford, "Copulatory Sequences and Sexual Struggles in Millipedes", Journal of Insect Behavior, 13. 2 (2000), 217230.

[11] Edward Barrows and Gordon Gordh, "Sexual Behavior in the Japanese Beetle, Popillia Japonica, and Comparative Notes on Sexual Behavior of Other Scarabs (Coleoptera: Scarabaeidae)", Behavioral Biology, 23. 3 (1978), 341-354. 
[12] Stephen Adolph and Monica Geber, "Mate-Guarding, Mating Success and Body Size in the Tropical Millipede Nyssodesmus Python (Peters) (Polydesmida: Platyrhacidae)", The Southwestern Naturalist (1995), 5661.

[13] Göran Arnqvist, "Pre-Copulatory Fighting in A Water Strider: InterSexual Conflict or Mate Assessment?", Animal Behaviour, 43.4 (1992), 559-567.

[14] Barbara Smuts and Robert Smuts, "Male Aggression and Sexual Coercion of Females in Nonhuman Primates and other Mammals: Evidence and Theoretical Implications", Advances in the Study of Behavior, 22 (1993), $1-63$.

[15] Paul Sherman and John Alcock, eds., Exploring Animal Behavior: Readings from American Scientist, Sinauer Associates, 1993.

[16] Nicola Graham-Kevan, and John Archer, "Control Tactics and Partner Violence in Heterosexual Relationships", Evolution and Human Behavior, 30.6 (2009), 445-452.

[17] Alexander Harcourt and Kelly Stewart, Gorilla society: Conflict, Compromise and Cooperation between Sexes, Chicago, IL, USA: The University of Chicago Press, 2007, 139-147.

[18] Alyn Brereton, "Coercion-Defense Hypothesis: the Evolution of Primate Sociality”, Folia Primatologica, 64. 4 (1995), 207-214.

[19] Kathelijne Koops et al., "Terrestrial Nest-Building by Wild Chimpanzees (Pan Troglodytes): Implications for the Tree-to-Ground Sleep Transition in Early Hominins", American Journal of Physical Anthropology, 148. 3 (2012), 351-361.

[20] Richard Alexander, "Evolutionary Change in Cricket Acoustical Communication". Evolution, 16. 4 (1962), 443-467.

[21] Huda Albahar, "Traditional Kuwaiti Houses", MIMAR: Architecture in Development, 13 (1984), 71-78.

[22] Subhi Almutawa, History of Architecture in Old Kuwait City, London: Saqi Books, 1994.

[23] Mohammad Alkhars and Maryam Alaqroqa, Old Kuwaiti House, Kuwait City: Center of Kuwaiti Studies and Research, 1999.

[24] Bechir Kenzari and Yasser Elsheshtawy, "The Ambiguous Veil: On Transparency, the Mashrabiy'ya, and Architecture", Journal of Architectural Education 56. 4 (2003), 17-25.

[25] Turkiyah Alenazy, "The Privacy and Social Needs of Women in Contemporary Kuwaiti Homes", Unpublished master thesis, Florida State University, (2007), 20-24.

[26] Friedrich Ragette, Traditional Domestic Architecture of the Arab Region, Sharjah, UAE: Axel Menges, American University of Sharjah, 2003, 75.

[27] Yaqoub Alhajji, Old Kuwait: Pictures and Memories, Kuwait City: Center of Kuwaiti Studies and Research, 1997, 155-157. 